\title{
Account of a female Pakistani Ph.D. scholar: An Autoethnographic exploration
}

\author{
Maimoona Saleem ${ }^{1}$
}

\begin{abstract}
There is a paucity of scholarship about what to anticipate in the course of a Ph.D. program, the emotional toll, and embodied experience of a Ph.D. candidate - research that unveils the innards of Ph.D. experiences, predominantly female academics and is more upfront about it is much lacking. A "reflexive narrative approach" combined with a feminist outlook, using memory as a data source has been used to station an understanding of experience into a broader array of literature. By this, the author explores the meaning of her doctoral journey. The author details and describes her experience, thoughts, and struggles with the self and others during this journey. Through this process, the author gains tenor, reckoning, and a better sense of direction for the future.
\end{abstract}

Keywords: Autoethnography, Ph.D. experiences, reflection, Pakistani, Female voice

\section{Introduction}

Autoethnography is a qualitative approach placed on self-reflection and writing to probe and explore personal and anecdotal experiences through social, cultural, or political contexts. In this method, the researcher is both the "investigator and the investigatee". Formerly, the autoethnographic approach was predominately used in the fields of sociology and anthropology. However, it is beginning to be treated as a valid method. There has been an upswing in using autoethnography by various disciplines like psychology, social sciences, and health sciences (Creswell, 2007; McIlveen, 2008).

The author in this paper employs a feminist outlook to station understanding of experience into a broader body of knowledge. This way, the author explores the meaning of her doctoral journey. A reflexive narrative approach to autoethnography (Ellis, 2004; Berry, 2006; Riessman, 2008) was culled, enabling the author to rummage through her memory as a data source. One of the leading authors and specialists on autoethnography as a research approach writes that autoethnography is "part auto or self and part ethno or culture" (Ellis, 2004, p. 37). She continues to define autoethnography as "writing about the personal and its relationship to culture.... that displays

1 Lecturer, Department of Management Sciences, Islamia College Peshawar.

\section{ARTICLE HISTORY}

17 Sep, 2020 Submission Received

17 Nov, 2020 First Review

28 Jan, 2021 Second Review

18 Feb, 2021 Accepted 
multiple layers of consciousness" (Ellis, 2004, p. 37). The differences are imperceptible in terms of how various authors define autoethnography; however, there is a consensus that it is a form of narrative inquiry (Chang, 2008, p.56). "Autoethnography also supplements social science research goals in a post-modern environment where there is not just one truth, but many emergent truths" (Wall, 2008, p.350).

The sections that follow employ an autoethnographic approach to demonstrate how students and researchers can employ it in various disciplines. The author details and describes her experience, thoughts, and struggles with the self and others during this journey. Through this process, the author gains tenor, reckoning, and a better sense of direction for the future.

\section{Motivation for The Study}

\subsection{Ph.D. and the "journey" metaphor}

Before I share my experience as a female Ph.D. candidate, I feel it is apt to see what others have written about their doctoral journeys. Since every doctoral experience is different and mystifying, the metaphorical expression of "the journey" is quite becoming, to put it mildly. If you are to type in the magical words "Ph.D. Journey" in a search bar, you will see thousands and thousands of links dedicated to this. I typed "my Ph.D. Journey" on Reddit, Quora, and google search engine and was not surprised to see so many blogs and pages dedicated to it. So, the trope of a journey, then, is rightly used for Ph.D. However, as I suspected it, I got 'nada' results in local doctoral experiences. I was hoping to come across what other local PhDs might have written about their Ph.D. experiences and struggles.

I know every experience is unique; however, some commonalities, the ones you would like to talk and read about, the same kind of travails sort of provides a venting mechanism. So, this is the story of my Ph.D. journey, one in innumerable others. It gives me the courage to share my account, thinking that others might follow suit and will narrate their versions of Ph.D. experiences. My motivation is to reflect on my experiences as a female Ph.D. scholar, the ebbs and flows of my doctoral journey.

\subsection{Sifting through the literature and setting the context}

The experience of my doctoral candidature was quite cloistering, but I am not an isolated case. The extant literature shows that doctoral students and their supervisors get bogged down with cultural, social, and economic isolation (McPhail-Bell \& Redman-MacLaren, 2019). Indeed, earning a Ph.D. is a crowning glory that is an arduous journey filled with numerous unforeseen events (Brydon \& Fleming, 2011). 
Recent years have witnessed a burgeoning scholarship investigating doctoral candidature experiences (Mason \& Hickman, 2019). There are studies on topics like Ph.D. candidates' mental health problems (Mackie \& Bates, 2019; Schmidt \& Hansson, 2018; Stubb, Pyhältö, \& Lonka, 2011) studies on the supervisory relationship (Wang \& Li, 2011; Mantai \& Dowling, 2015), studies on people with learning disabilities (Durell, 2016), and satisfaction among students (Barnes \& Randall, 2012). However, there is a relative dearth of studies on female doctoral students' individual experiences (Ramanayake, 2020), particularly in the context of Pakistan.

While sifting through literature about doctoral students' individual experiences, especially female academics, I felt a remarkable paucity of scholarship. The lack of literature rings especially true in my context while I was doing a Ph.D. at a private university in Khyber Pakhtunkhwa, Pakistan. Thus, I decided to embark on yet another journey of presenting an autoethnographic account of my lived experience as a Ph.D. candidature.

The postmodern epoch paved the way for the growth of critical theories and their scholarly inquiry application, thus opening avenues of research strategies. For example, "feminist theory, and feminist research, feminist autoethnography using multiple research techniques, has grown in reaction to the male-oriented perspective that has predominated in the development of social science" (Neuman, 1994, p. 72). Numerous feminist authors presently beckon for research that springs from one's own experience (Ellis, 2004). As opposed to "the dominant, objective, competitive, logical male point of view, feminist researchers emphasize the subjective, empathetic, process-oriented, and inclusive sides of social life" (Neuman, 1994, p. 72).

A feminist autoethnography discloses the experiences that may be profoundly intimate to provide narrative accounts to document and share these experiences. Case in point, Lorde's (1997) “The Cancer Journals is representative of the significance of feminist autoethnography in documenting her experience as a Black woman diagnosed with cancer, as are Stern's (2014) accounts of her experiences with childhood trauma and abuse."

The focus on my accounts as a female Ph.D. candidate tries to serve a similar purpose. Different women having a full-time career and a family to look after are balancing a career, family, and atop that Ph.D. may identify with my own experiences. I chose the feminist lens to present my experience to contemporary scholarship and thought. The feminist standpoint enabled me to extrapolate my experiences as a female and are based on the notion that "women and men interpret and experience the world around them differently" (Smith, 1987, p.351). 
One might ask, what amounts to a research feminist? A textbook description of feminist research is that it is "done by, for, and about women." Also, "feminist researchers produce feminist research" (Robbins, 1996, p. 170). However, there necessitates a universal definition of "feminist research" (or "feminism," for that matter); however, several authors steer to specific components as distinguishing features. Furthermore, "these traits delineate feminist research from traditional social sciences research, research that studies women, or research that attends to gender without an agenda for change" (Robbins, 1996, p. 170). What makes feminist research exclusively feminist are "the kinds of questions, methodologies, knowledge, and purpose of the research process" ("Introduction to Feminist Research", n.d.).

In the studies by (Oswalt \& Riddock, 2007; Toews, Lockyer, Dobson, Simpson, Brownell, Brenneis, MacPherson \& Cohen, 1997) a higher level of stress was reported by women than men in doctoral programs. A core reason mentioned for the increased levels of stress among women was that the female doctoral candidates had the additional responsibility to an "already existing set of caretaking and other life roles” (Hyun, Quinn, Madon \& Lusting, 2006; Stratton, Mielke, Kirshenbaum, Goodrich \& McRae, 2006). Furthermore, Smith, Maroney, Nelson, Lable, and Abel (2006) said that female Ph.D. scholars also have to worry about their kids, in-laws, aging parents, and spouses. These multifarious and sometimes overlapping responsibilities can affect female scholars' mental health and the possibility of finishing their doctoral candidature (Hyun et al., 2006). Owing to the juggling of roles, matching their personal and professional lives becomes tricky, "which leaves them to endure inter-role conflict between their personal and academic roles. This interplay between the different roles and lack of time and energy often leads to anxiety, causing physical and mental health problems" (Johnson, Batia \& Haun, 2008, p.288).

This study is an attempt to add to the body of literature and offers a profoundly esoteric account. In this paper, I try to reflect on my experiences as a female Ph.D. scholar, the ebbs and flows of my doctoral journey. The use of autoethnography provided converging on my doctoral research experiences to be the "unit of analysis" (Ellis \& Bochner, 2000). This paper is meant for Ph.D. scholars but, most importantly, Ph.D. supervisors and committees. Every Ph.D. journey is different, but I hope that there is enough conceptual leeway given. As academicians travel to universities in and out of their country, the host university may have a Ph.D. protocol slightly different (Ban \& Scott, 2021). This article is my account as a female Pakistani Ph.D. scholar who was enrolled in a regular Ph.D. program at a private university in Khyber Pakhtunkhwa, Pakistan, with one-year coursework, which was followed by a comprehensive exam under the guidance of one supervisor. So, this may very well be different from the contexts of those reading this. But contextual diversity is merely one fashion in 
which $\mathrm{Ph}$. D. experiences vary.

\subsection{The decision to officially pen down my experience}

It was a hot Friday afternoon of July, in lockdown amid a coronavirus outbreak. I was lying in my room flipping through my cellphone, texting with a friend who was finalizing her Ph.D. dissertation. She was overwhelmed and exhausted, she said. She has two toddlers, a boy, and a girl, and she felt she did not have enough hours in the day; as she fretted, she is not doing it "enough." The conversation transported me back to the year 2018, when I was in the final stages of my Ph.D., awaiting public defense. As I am writing this, I want anyone who is reading this, who is either thinking of pursuing a doctorate or is in the midst of one, to tell them that whatever they are feeling is expected and natural, you will pull through, and I know exactly how you feel right now. As I type and reflect, it is liberating and cathartic to share what I felt during my Ph.D. process. As I look back, the depth of emotions ricochets my chest cavity. I want to write autoethnographically about my Ph.D. journey as a female academic to make sense for myself and others.

First off, I want to unveil the innards of my Ph.D. experience as a female scholar and be more upfront about it which is pretty hard to do in the writeup of a doctoral dissertation. After experiencing it firsthand, Ph.D. scholars frequently suffer from anxiety that they are merely getting by and not doing it "enough." I need to explicate that this predicament of dangling disarray is natural, that becoming succumbed midway does not insinuate never crossing the finish line, and that the goal may well be distinct from that which was initially envisioned. Like (Pretorius, Macaulay \& Cahusac de Caux, 2019) reflected on their respective doctoral journeys in the form of a collaborative autoethnography (CAE), I also intend to share my individual experience, comfort and explain the metamorphosis from a Ph.D. scholar to an independent researcher. I want to travel back in time, use memory as my data source, to make sense of the "journey" for the reader. Mainly, I am penning down my thoughts and experiences for $\mathrm{Ph} . \mathrm{D}$. students and prospective students to grasp this: here is my unedited, heartfelt, and nuanced experience.

Though a tad bit enthusiastic on my part, I would like to introduce a type widely missing from the academic scholarship that is to have stories of Ph.D. scholars' research encounters and experiences, similar to adventure anecdotes rather than dummies-101. Similar to adventure stories, the before-mentioned narratives would lend a lens into the junctions of various personalities and "the" exclusive Ph.D. experience. Thus, the Ph.D. committees and students' supervisors might have a different take on it, becoming slightly more heedful to the hurdles and problems their supervisees might be facing, utterly different from their own. As every individual experience is unique 
and honest regarding student evenhandedness, it is imperative to understand that each $\mathrm{Ph} . \mathrm{D}$. journey is unique, and one size does not fit all. So, the supervisors attempting to hobnob scholars with their anecdotes donning rose-tinted glasses and banking essentially on their own experiences as an archetype for supervision should rethink.

\subsection{Autoethnography as a methodology}

Autoethnography was formerly used as a research's vernacular expression by Hayano in 1979 to describe researchers who "conduct and write ethnographies of their people" (Hayano, 1979, p.99). Subsequently, it emerged as a methodology recognized by diverse titles and forms. However, they all have in common the apparent introduction of the "self (auto) in an investigation (graphy) of the cultural process (ethno) albeit with varying emphasis on each component" (Ellis \& Bochner, 2000, p.111). They proffer an extensive list of terms umbrellaed in the scaffold of autoethnography, including first-person accounts, personal narratives, self-phenomenology, self-ethnography, critical autobiography, and complete member research, indigenous ethnography, performance autoethnography, and reflexive ethnography. The investigator will study his or her experiences (life history) or culture, a culture which the researcher is a part of and has fully embraced, or someone else's culture, as it coheres with the "self" of the researcher (O'Byrne, 2007). The methodology demands the author to "scrutinize, publicize, and reflexively rework their self-understandings as a way to shape the understandings of and in the wider world" (Butz \& Besio, 2009, p. 1660).

The postmodern "crisis of representation" of the 80s goaded this form of inquiry, where autoethnography glaringly splits the disunion between researcher and researched, confronting and completely disbanding the idea of a detached, objective researcher -"autoethnography is one of the approaches that acknowledges and accommodates subjectivity, emotionality, and the researcher's influence on research, rather than hiding from these matters or assuming they don't exist" (Ellis, Adams, \& Bochner, 2010, p. 2).

In autoethnographic writing, the investigator may be the sole participant or one of many, as in Collaborative autoethnography (CAE). Ellis and Bochner (2000) advocated the form of autoethnography, which according to some scholars, should be regarded as Evocative Autoethnography (Anderson, 2006). However, Ellis and Bochner (2000) contend that all autoethnography is by quality evocative in which the researcher is often the singular subject. They define the researcher teetering externally on social and cultural slants of personal experience, then glances internally unveiling a vulnerable self. By way of this back-and-forth process, differences between the personal and cultural become foggy. The analysis may be explicit or obscure, partly depending on "wherein the continuum of art and science you want to locate yourself" (Ellis \& 
Bochner, 2000, p. 750).

Standing at the other end of the continuum, Anderson (2006) presents analytic autoethnography in contrast to the method of autoethnography supported by (Ellis and Bochner, 2000). Anderson (2006) approves the role of the researcher as the subject; however, he necessitates to come full circle (going back to traditional ethnographic roots), asking for a theoretically grounded analysis and role of other participants. "The definitive feature of analytic autoethnography is this value-added quality of not only truthfully rendering the social world under investigation but also transcending that world through broader generalization" (Anderson, 2006, p.388).

On the contrary, Burnier (2006) states that analytic autoethnography stifles and inhibits the personal or self in the context of research. In a world which is pervaded with statistical models and numbers, she as a political scientist embraces the 'I' in her pedagogy and writing, maintaining that "autoethnographic writing is both personal and scholarly, both evocative and analytical, and it is both descriptive and theoretical when it is done well" (Burnier, 2006, p. 414).

Autoethnographic investigators employ slightly unconventional ways of presentation, such as art, drama, or writing, as additional vivisection of popular modes of conducting and delivering research and broadening the prospective audience (Ellis et al., 2010; Jones, 2005). In addition to not-so-conventional modes of presentation, writing in the first-person is usually advocated as this tends to be more evocative and personal, aiming to enmesh the reader fervently as a way of causing change. It may apply traits of narration (characters, storyboard) and tweaking of "authorial voice". My use of introspective passages in this piece is an example of "showing... to bring readers into the scene" Ellis et al. (2010, p.4), peppered with the "telling" - text that presents impersonal distance for the reader. These methods incite the reader to enmesh in an unusual and conceivably more meaningful way with scientific research and writing, in this case, the treatment of individual accounts to probe the journey of Ph.D. scholars during their doctoral candidature.

Autoethnography is an engaging qualitative inquiry that lends a voice to individual experience (Wall, 2008). Reed-Danahay (1997), described that the quality that divorces autoethnography from other qualitative inquiries is its attention "on the individual within a given social context: the auto within the ethno" (p.9). While some view a personal narrative and autoethnography to be alike (Ellis \& Bochner, 2000), others see autoethnography as a way of "explicitly linking concepts from the literature to the narrated personal experience” (Holt, 2001; Sparkes, 1996) and promote this approach as "rigorous and justifiable as any other form of inquiry" (Duncan, 2004, p.39). 
In this paper, I draw on the evocative form of autoethnography to reflect on my lived experiences. From an epistemological perspective, autoethnography can be viewed as the quest of "creat[ing] verisimilitude rather than making hard truth claims" (Grant 2010, p. 578) while it also, conceivably, "seeks to elicit caring and empathy, [as] it dwell[s] in the flux of lived experience" (Ellis \& Bochner 2006, p. 431). The aftermath is the emergence of idiosyncratic, eccentric texts far from the "standard boring writing of the academy" (Sparkes 2007, p. 541). For instance, his autoethnography titled: "Autoethnography for Extraterrestrials" (Heywood, 2020) "explores a creative-artistic approach rooted in autoethnography, using satire and literary tropes from science fiction and fantasy".

Another more serious example by (McMillan \& Ramirez, 2016) titled, "Autoethnography as Therapy for Trauma" uses autoethnographic where the authors "put forward the proposition that the act of healing cannot be private, for risk of perpetuating current discourses of shame associated with trauma, but instead to make visible oppressive, genderized, and structural acts that are ignored by medical approaches" (McMillan \& Ramirez, 2016, p.432).

Autoethnography also comes with some criticism. Opponents of this methodology suggest that it has shortcomings with its myopic focus on the self and narratives that could be a bit overkill rather than focusing on cultural interpretation (Chang, 2008). Also, the element of vulnerability that comes with divulging inner feelings and raw emotions, one is expected to be honest when sharing personal accounts. Which in turn surrounds autoethnography with some ethical concerns. For instance, Wyatt (2006) opines that the author penning down his or her autoethnography may be faced with a dilemma seeking consent for publication from those actors in the author's story.

Ellis (2007) talks about "relational ethics that envelopes the ethics required in writings about personal experiences where people close to us are included" (p.4). She takes account of the predicament if the author should request the consent of the people involved in autoethnographic narratives, but there is no conclusive answer to this or the other ethical concerns that may emerge when involved in autoethnography. However, while Ellis (2007) substantiates that, regrettably, there is no general rule that could guide you in such situations, however, it is common sense not to cause any harm to the person involved; you should seek consent if the need be. Though writing autoethnographically requires you to be ethical and honest about the events described (Méndez, 2013). "Autoethnography can be considered an ethical practice" (Ellis, 2007, p. 26).

Furthermore, another issue that mars autoethnography is that some authors consider it too vain and egocentric to write about yourself (Krizek, 2003); however, 
the author also continues to state that no matter how personal autoethnography is, it should relate to a deeper element of life. In this article, I intend to bring to the fore the travails, the emotional and psychological sacrifices that Ph.D. students have to endure that are not commonly addressed. Even advocated the use of autoethnography for narrating our dreams and their storyline(s) "because dreams can cut through all the hubbub and haze and shadowy ambiguity of everyday life" (Poulos, 2006, p. 113). Correspondingly Richardson (1994) stated that "by telling stories we validate our identity and pain, which may provide a way to developing a critical consciousness".

Writing my autoethnography I intend to share my experience as a female Ph.D. candidate and share my travails as a female doctoral candidate. Autoethnography is a navel-gazing method used to obtain "cached" data which cannot be readily recognized. Such an investigation "...provide the researcher a window through which the external world is understood” (Ngunjiri, Hernandez, \& Chang 2010, Section 2, para 1). By reflecting on my Ph.D. journey, I came to a more profound understanding of the research and myself as a person and as a woman. Like Boylorn (2006) submitted that autoethnography is a methodology of what Hooks (2000) describes as "repositioning", which allows the author to be empowered to tell what has not always been easy to tell (Tsalach, 2013). Thus, writing this autoethnography allowed me to break free and to pen down what I felt as a female academic. Choosing this path wasn't my call (I delve into this later in the article); it was my father's, and while I did complete my $\mathrm{Ph} . \mathrm{D}$., I was experiencing some life-changing events my father fell seriously ill and passed away. So, this narrative is me trying to 'reposition' myself, allowing myself to vent and talk about emotional experiences and life-changing events (exceptional occurrences) that are not easy.

\subsection{1 "Exceptional Occurrences" as analysis and interpretation strategy}

There is a lack of scholarship on data analysis in autoethnography about how to go about it, but Chang (2008), in her book "Autoethnography as Method," suggested ten strategies that could be employed for data analysis in an autoethnographic study. These include: "(1) search for recurring topics, themes, and patterns; (2) look for cultural themes; (3) identify exceptional occurrences; (4) analyze inclusion and omission; (5) connect the present with the past; (6) analyze relationships between self and others; (7) compare yourself with other people's cases; (8) contextualize broadly; (9) compare with social science constructs and ideas, and (10) frame with theories (p.131)." The earlier strategies suggested by Chang (2008) are more "analysis-oriented, and the following ones are more interpretation-oriented" (p. 131).

A life-changing experience is an "event experienced by a person altering his/ her life or circumstances in a substantial way," to quote the internet. The experience 
may be insignificant to others but bears a tremendous sentimental, psychological, and physical effect on the one who experiences it. A life-changing experience could be an action, a situation leading to a decision, or meeting with someone. Chang (2008) asserts that "after life-changing experiences, people rarely go back to their old selves, but rather move on to a new direction. For this reason, identifying exceptional occurrences in life can provide tremendously useful information on self' (p.133).

The "exceptionalities in my life" were giving Ph.D. a go, physical and mental well-being during the candidature, and atop all this losing my father. Consequently, these "exceptionalities in life" shaped my data analysis and interpretation.

\section{Scholastic Implications}

\subsection{Theoretical contribution}

Autoethnography is a burgeoning qualitative research method that empowers the writer to write in a profoundly idiosyncratic manner, pulling on his or her experience to proffer knowledge about a societal phenomenon. "Autoethnography is grounded in postmodern philosophy and is linked to a growing debate about reflexivity and voice in social research. It attempts to recognize the intricate nexus between the personal and the cultural and make room for nontraditional forms of inquiry and expression" (Wall, 2008, p.146).

The theoretical contributions of this study are threefold.

First, this study offers a theoretical contribution into autoethnographic praxis employing "wide-angle lens, focusing outward on social aspects of personal experience; then inward, exposing a vulnerable self, refracting cultural interpretations" (Ellis \& Bochner, 2000, p. 739). Recognizing the novelty (newness) of autoethnography as a method that blends ethnography and autobiography characteristics - is gaining momentum partially because of the opportunity it presents for authors, writers, performers, and what have you to reveal critically upon their personal and professional experiences.

Second, the postmodern age warranted the rise of critical theories and their academic inquiry application, thus opening avenues of research strategies. For instance, "feminist theory, and feminist research, feminist autoethnography using multiple research techniques, has grown in reaction to the male-oriented perspective that has predominated in the development of social science" (Neuman, 1994, p. 72). Many feminist authors now call for inquiry that springs from one's own experience (Ellis, 2004). As opposed to "the dominant, objective, competitive, logical male point of 
view, feminist researchers emphasize the subjective, empathetic, process-oriented, and inclusive sides of social life" (Neuman, 1994, p. 72). Feminist autoethnography unravels the experiences that may be deeply personal to provide narrative accounts to document and share these experiences. The focus of my narratives as a female Ph.D. scholar strives to serve a similar purpose. Other women having a full-time career and a family to look after are juggling a career, family, and atop that Ph.D. may identify with my own experiences. I picked feminist lens to bear on my experience to the current scholarship and thought. The feminist standpoint enabled me to extrapolate my experiences as a female and are based on the notion that "women and men interpret and experience the world around them differently" (Smith, 1987, p.351).

What amounts to a research feminist? A textbook explanation of feminist research is that it is "done by, for, and about women." Another explanation is that "feminist researchers produce feminist research" (Robbins, 1996, p. 170). There lacks a unanimous definition of "feminist research" (or "feminism," for that matter); however, several authors steer to specific components as distinguishing features. Moreover, "these features characterize feminist research from traditional social sciences research, research that studies women, or research that attends to gender without an agenda for change" (Robbins, 1996, p. 170). What makes feminist research exclusively feminist are "the kinds of questions, methodologies, knowledge, and purpose of the research process" ("Introduction to Feminist Research”, n.d.)

The Ph.D. for me was not merely a degree; it was my way of venerating my father. Using a feminist lens allowed me to view my own beliefs about what a doctoral degree means, my role as a daughter and a woman, and the need for additional support. Placing the doctoral process inside a feminist paradigm enabled the author to depict her experiences as a woman with authenticity and vulnerability not often expressed in more conventional research methods. For me, trying to bear my innards by writing from the heart has brought me one step closer to finding my lost feminist voice.

Third, using memory as a data source. Historically, data in ethnography mostly emerge from field notes taken during participant observation, in-depth interviews, diaries, and document and artifact analysis (Mayan, 2001; Morse \& Richards, 2002). So, researchers employing autoethnography have stayed staunch to these traditions. For instance, Sparkes (1996) utilized data from excerpts from his diary, medical history, newspaper clippings covering his sports career, and the chronic condition that quelled it. Ettorre (2005), working similarly, drew data from missives, journals, articles, and lab results to base the investigation on the experience of her sickness. Holt (2001) used data from his journal entries for deliberations around his teaching practice. Duncan (2004) used a comprehensive journal and e-mails, memos, and sketches to evaluate her professional work. However, no one among these researchers 
unequivocally relied on "memories" as data in their work, save only Ettorre (2005) has admitted "remembering as part of the analysis process" (p.45). Thus, the prerequisite to provide 'hard' data to be at hand to make interpretations and present claims remain. Muncey (2005) proposed the use of snippets and artifacts in a study and suggested that "they can be important [for the legitimation of autoethnography] if memory and its distortions appear to be critical features of the process" (p. 1). In the same vein, Duncan (2004) as a traditional auto-ethnographer asks for the use of "multiple sources of evidence to support a personal opinion, suggesting the need for hard evidence to support soft impressions" (p.45)."

Wall (2008) addresses the significance of utilizing multiple data sources and has an intriguing argument about employing memory as a data source. (Wall, 2008) was able to defend her use of personal memory as a source of rich data.

"If a researcher had interviewed me about my experiences as an adoptive mother -recorded $\mathcal{B}$ transcribed it, it would have legitimacy as data-though both (interview transcript, $\mathcal{E}$ my autoethnographic text) would be based on the same set of memories" (Wall, 2008, p.45).

Wall (2008) further says that her supervisory board told her to "justify her strategy of using memories as data." Furthermore, she says that save that the data about someone's "individual experience" is gathered and analyzed by another researcher, it somehow fails to warrant as "legitimate". Sparkes (2000) shared his experience of using his published autoethnography in one of his undergrad classes, saying that his pupils do not contemplate of his autoethnography as research. Nevertheless, when questioned if it would be "research if someone else had interviewed a man named Andrew Sparkes; collected his medical records, diary excerpts, and newspaper stories; analyzed the collection, and written it up, the class says yes" (Wall, 2008, p.45).

For the current study, if another researcher had interviewed me asking about my experience as a female Ph.D. scholar, recorded and transcribed it, this would have been deemed legitimate, even though corpus of data obtained in both the cases (interview transcript and my autoethnographic account) had the identical source that is the same set of memories.

\section{Issues of Trustworthiness}

The guidelines for ascertaining validity, reliability, and generalizability, aka rigor in quantitative research, are well-established. However, some scholars are of the view that the same criteria of rigor could be applied to qualitative inquiry (Winter, 2000; Morse, Barrett, Mayan, Olsen \& Spiers, 2002; Golafshani, 2003) however, while other dispute this take and ask for different set of rules (Lincoln \& Guba, 1985; Sandelowski, 1986; Koch \& Harrington, 1998; Tracy, 2010). While some renounce the 
Table 1: Summary of Theoretical Contributions

\begin{tabular}{|c|c|c|}
\hline Gap & Past literature & Insights from this study \\
\hline $\begin{array}{l}\text { Bringing } \\
\text { the blend of } \\
\text { ethnography } \\
\text { and autoeth- } \\
\text { nography to } \\
\text { the fore }\end{array}$ & $\begin{array}{l}\text { Recent years have witnessed a } \\
\text { burgeoning scholarship investigating } \\
\text { doctoral candidature experiences } \\
\text { (Mason \& Hickman, 2019). There are } \\
\text { studies on topics like PhD candidates' } \\
\text { mental health problems (Mackie \& } \\
\text { Bates, 2019; Schmidt \& Hansson, } \\
\text { 2018; Stubb et al., 2011) studies on } \\
\text { the supervisory relationship (Wang } \\
\text { \& Li, 2011; Mantai \& Dowling, } \\
\text { 2015), studies on people with learn- } \\
\text { ing disabilities (Durell, 2016), and } \\
\text { satisfaction among students (Barnes } \\
\text { \& Randall, 2012). However, there is } \\
\text { a relative dearth of studies on female } \\
\text { doctoral students' individual experi- } \\
\text { ences, particularly in the context of } \\
\text { Pakistan. }\end{array}$ & $\begin{array}{l}\text { Recognizing the novelty (newness) of } \\
\text { autoethnography as a method that blends } \\
\text { ethnography and autobiography charac- } \\
\text { teristics- is gaining momentum partially } \\
\text { "because of the opportunity it presents } \\
\text { for authors, writers, performers, and } \\
\text { what have you to reveal critically upon } \\
\text { their personal and professional experienc- } \\
\text { es" (Pace, 2012, p.1). }\end{array}$ \\
\hline $\begin{array}{l}\text { A reflexive } \\
\text { narrative } \\
\text { approach } \\
\text { employing a } \\
\text { Feminist lens }\end{array}$ & $\begin{array}{l}\text { The postmodern age warranted the } \\
\text { rise of critical theories and their aca- } \\
\text { demic inquiry application, thus open- } \\
\text { ing avenues of research strategies. For } \\
\text { instance, "feminist theory, and femi- } \\
\text { nist research using multiple research } \\
\text { techniques, has grown in reaction to } \\
\text { the male-oriented perspective that has } \\
\text { predominated in the development of } \\
\text { social science" (Neuman, 1994, p. 72). } \\
\text { Many feminist authors now call for } \\
\text { inquiry that springs from one's own } \\
\text { experience (Ellis, 2004). As opposed } \\
\text { to "the dominant, objective, com- } \\
\text { petitive, logical male point of view, } \\
\text { feminist researchers emphasize the } \\
\text { subjective, empathetic, process-orient- } \\
\text { ed, and inclusive sides of social life" } \\
\text { (Neuman, 1994, p. 72). }\end{array}$ & $\begin{array}{l}\text { I picked feminist lens to bear on my } \\
\text { experience to the current scholarship } \\
\text { and thought. The feminist standpoint } \\
\text { enabled me to extrapolate my experi- } \\
\text { ences as a female and are based on the } \\
\text { notion that "women and men interpret } \\
\text { and experience the world around them } \\
\text { differently" (Smith, 1987, p.351). Using } \\
\text { a feminist lens allowed me to view } \\
\text { my own beliefs about what a doctoral } \\
\text { degree means, my role as a daughter, as } \\
\text { a woman, as a female academic and the } \\
\text { need for additional support. Placing the } \\
\text { doctoral process inside a feminist para- } \\
\text { digm enabled the author to depict her } \\
\text { experiences as a woman with authenticity } \\
\text { and vulnerability not often expressed in } \\
\text { more conventional research methods. }\end{array}$ \\
\hline
\end{tabular}




\begin{tabular}{|c|c|c|}
\hline $\begin{array}{c}\text { Using 'mem- } \\
\text { ory as a data } \\
\text { source' }\end{array}$ & $\begin{array}{c}\text { Historically, data in ethnography } \\
\text { mostly emerge from field notes taken } \\
\text { during participant observation, } \\
\text { in-depth interviews, diaries, and doc- } \\
\text { ument and artifact analysis (Mayan, } \\
\text { 2001; Morse \& Richards, 2002). So, } \\
\text { researchers employing autoethnog- } \\
\text { raphy have stayed staunch to these } \\
\text { traditions. (Wall, 2008) was able to } \\
\text { defend her use of personal memory } \\
\text { as a source of rich data. }\end{array}$ & $\begin{array}{c}\text { There is a paucity of literature that } \\
\text { utilizes it for empirical investigation } \\
\text { using 'memory as a data source' based } \\
\text { approach. In this study the author has } \\
\text { rummaged through her memory as a data } \\
\text { source. }\end{array}$ \\
\hline
\end{tabular}

idea of usance of any such criteria altogether (Schwandt, 1996; Hope \& Waterman, 2003; Bochner, 2000; Rolfe, 2006)

Notwithstanding the uptick in its popularity, autoethnography, on the flip side, is deemed as quite controversial and a 'self-indulgent' approach to qualitative inquiry. Autoethnography is viewed as something analogous to 'navel-gazing' autobiography than proper social scientific research in some fractions. However, this approach has had its fair share of criticism, especially regarding questions of validity. Wall (2008) writes that still, well-renowned qualitative research methods face disapproval since they fail to acquiesce traditional research criteria. Autoethnography being a profoundly individualized approach to qualitative inquiry, is even more susceptible to criticism owning to the befogging researcher/subject boundary. Using 'self' as a data source is often frowned upon in the research circles. Moreover, an autoethnographic account is a piece of work written in a highly personal and evocative way. This personalized form of expression challenges the "old orthodoxy of the researcher as neutral, objective and textually absent, leaving the author vulnerable to charges of being irrational, particularistic, private, and subjective, rather than reasonable, universal, public, and objective" (Greenhalgh, 2001, p.55).

Tracy (2010) submits that the criteria to evaluate quality in qualitative inquiry are contextually situated; however, she acknowledges a baffling number of criteria for ensuring merit in a qualitative study that muddles the process of establishing rigor. Tracy (2010) proposes eight criteria to render a straightforward assortment of generic criteria for qualitative rigor. These criteria comprise a "worthy topic, rich rigor, sincerity, credibility, resonance, significant contribution, ethical, meaningful coherence" (p. 838). However, with a caveat, she advises against adhering to any such list of criteria too firmly. Tracy (2010) refers to Ellis (2007) as stating that "good qualitative methodologists, undertake a research project in a way they conduct themselves in their personal lives and seek the good with the key of being honest towards self and the audience for whom the research is intended" (p. 26). 
In this paper, I have tried to bring an authentic self to the reader, reflecting on the Ph.D. candidature experience as a female. The purpose was to bring to the fore the vulnerable side of a Ph.D. scholar. As an author, I have tried to adhere to Tracy's (2010) criteria. This study's topic is worthy, has rigor, sincerity, credibility, resonates with the readers, is a significant contribution, is ethical, and has meaningful coherence.

\section{Analysis and Interpretation}

There is not much written about data analysis in autoethnography about how you do it, but Chang (2008), in her book "Autoethnography as Method," suggested ten strategies that can be employed for data analysis in an autoethnographic study. These include: "(1) search for recurring topics, themes, and patterns; (2) look for cultural themes; (3) identify exceptional occurrences; (4) analyze inclusion and omission; (5) connect the present with the past; (6) analyze relationships between self and others; (7) compare yourself with other people's cases; (8) contextualize broadly; (9) compare with social science constructs and ideas, and (10) frame with theories." The earlier strategies suggested by Chang (2008) are more "analysis-oriented, and the following ones are more interpretation-oriented" (p. 131).

In this paper, I employed "Identify Exceptional Occurrences" as my analysis and interpretation strategy. Chang (2008) asserts that "after life-changing experiences, people rarely go back to their old selves, but rather move on to a new direction. For this reason, identifying exceptional occurrences in life can provide tremendously useful information on self" (Chang, 2008, p.133). So, I structured my data analysis and interpretation around these "exceptional occurrences in life."

Also, I will be relying on my memory as a data source. I used the power of recollection to pen down my doctoral experience. "Recollection reflects the retrieval of qualitative information about a specific study episode, such as when or where an event took place" (Yonelinas, Aly, Wang, \& Koen, 2010). There is proven merit in banking on memory in autoethnographic work, so, like Ottenberg, I work my memories when I write, though when I cannot substantiate their veracity with written data, because "I remember many things ... [and] I am certain that they are correct and not a fantasy" (Ottenberg, 1990, p. 144).

Placing the doctoral process inside a feminist paradigm enabled the author to depict her experiences as a woman with authenticity and vulnerability not often expressed in more conventional research methods. For me, trying to bear my innards by writing from the heart has brought me one step closer to finding my lost feminist voice - my role as a daughter and a woman, and the need for additional support.

The three exceptional occurrences in my life during my Ph.D. journey comprise: 
1. Thrown into the deep end: Ending up in a Ph.D. program.

2. Repeat after me! Ph.D. takes an emotional toll on you, and we should talk about it.

3. Becoming the first female Ph.D. in my family and losing my father.

\subsubsection{Thrown into the deep end: Ending up in a Ph.D. program}

Hailing from a family where my late father was a Harvard University fellow who did his Ph.D. in philosophy from the University of Hawaii. He was a luminary, one who attained a significant stature in philosophy and left a permanent mark in the minds of those who knew him. One would think that my choice of pursuing a doctorate would come naturally to me is far from the truth. I was freshly out of university, did my MBA, and had a rather nonchalant attitude to life.

I never imagined I would end up in a Ph.D. program. It was not for me, I felt. Out of sheer respect for my father's wish, I ended up in a Ph.D. program (exceptional occurrence).

During my high school years, I was a pre-med student and had every intention of becoming a medical doctor. However, life had other plans for me. I did not score well on the entrance exam that could have landed me in a good med school. So, I decided to change course and opted for business studies for my bachelor's and master's degrees. So, I finished my master's with magna cum laude. I was used to being successful in academia. When I got enrolled in the doctoral program, I saw this process as a natural progression, a step up from a Masters' level. However, I was oblivious that a doctoral program is an entirely different ball game. I was naive that a doctoral student has to experience social, cultural, and economic isolation.

Being their first-born daughter, I grew up in the shadows of academically sound parents, especially my father, a prolific author and researcher in his own right. My biggest struggle has been to create my own identity. I had to take this leap of faithsomeone who was barely out of grad school to becoming an academic to building self-esteem and determination in my intellectual comprehension and investigative abilities. I struggled and combatted with an academic identity crisis and was plagued by the thought of who am I? I got pigeonholed, and my own identity had become entirely defined by my Ph.D. work. I had created a persona defined by just one aspect of my life. When confronted by mediocre outcomes or missed attempts, I interpreted these outcomes to sign that my whole identity was a failure or was insufficient. As a result, my psychological and mental attitude ebbed and flowed to the pulse of my $\mathrm{Ph}$.D. So, I wanted these struggles to see the light of day as getting so worked up because of the stress, and finding ways to deal with them can help us grow strong. 
So, there I was sitting in my very first class as a Ph.D. candidate for my coursework. I felt so out of place, mainly because there was only one other female scholar in our class; I remember the very first assignment our teacher assigned to us. "Why do you want to do a Ph.D.?", I paused for a while, the silence interspersed with long sighs; I said to myself, "the heck I know". I brought home the assignment, which was due in the next class; I was on my computer, white screen of the word processor looking right back at me, the little cursor pointer doing its thing, blinking, waiting for me to type in the answer.

5.1.2 Repeat after me! Ph.D. takes an emotional toll on you, and we should talk about it

Fast forward one year, my coursework was complete, I nailed my comprehensive exam, and the long road laid bare the challenge of deciding on a Ph.D. topic and starting the research process. I still remember, my class-fellows were so on point. There were times when my motivation was flagging, but quitting was not an option. I knew I was not working hard enough, not reading enough- was just not 'enough'. I did not understand how to apply myself when I did not have a clear direction or aim.

Unfortunately, no one likes to talk about mental health issues and the struggle that surrounds Ph.D. students. When we talk about Ph.D. candidature, it is a crowning achievement, a historic decision, a milestone, and many sacrifices have to be made to achieve this milestone. According to one of the studies" ${ }^{2}$ " nearly one-third of Ph.D. students are exposed to the risk of developing a common psychiatric disorder like depression. Even though the result from the study came from a small sample of 3659 students at universities in Flanders, Belgium, 90\% of whom were studying the sciences and social sciences- however, the result adds to the pool of literature about the pervasiveness of mental health issues in academia."

A Ph.D. is hitting an academic home-run, but there is also a dark side to it; the road toward entering the homestretch shows an arduous display of resilience and perseverance. To become enlightened has a cost; it is exhausting, depressing, disheartening, challenging, and empowering, and liberating. It is common knowledge that getting a doctorate is hard. However, when a scholar decides to enter into a Ph.D. candidature, it is a given that the ride will not be easy, but what no one talks about is the dark side of the candidature- a psychological one. There are times when scholars need to have nerves of steel not to crack under pressure. However, not everyone is so fortunate, a recent incident where a Ph.D. scholar resorted to suicide as "she was unable to complete her Ph.D. in the last 15 years and was reportedly harassed by

2 "Doctoral Student Commits Suicide In Karachi - Daily Times", Daily Times, Last modified 2021, https:// dailytimes.com.pk/655245/doctoral-student-commits-suicide-in-karachi/. 
her thesis supervisor. She was also suffering from psychological and family issues".

The Ph.D. process brings about a metamorphosis, so there have been some significant shifts and changes throughout my candidature. I have been more empathetic for one. This journey is gruesome, one has to survive, but I would like to exhort supervisors not to lose their understanding and compassion for those under their wings. It is one thing to be hyper-critical and give a candidate a hard time, but to view a journey through others' lenses, which may be very different from ours, is needed.

During my Ph.D. years, there were times when I felt so helpless. During these low times that out of sheer frustration, I was on a road of self-destruction; I was binge-eating, not looking after my mental and physical health, and had developed this intense hatred of the process. My deteriorating mental health was another exceptional occurrence. My invective as a female academic was directed toward this whole higher education system. I isolated myself; I felt so defeated. I accepted the fact that maybe I was not cut out for Ph.D. I was in such a toxic place, but quitting was not an option because I did not want to cause disappointment to my parents, especially my father.

When I was through with my Ph.D., I realized that many of my friends were experiencing significant mental health difficulties. One of my friends started experiencing hair loss due to constant stress. I discovered that mental health issues are so rampant among doctoral candidates, yet no one likes to talk about it, and they are normalized in a sense then; if you don't lose sleep over it and develop insomnia, it is considered you are not putting in enough effort. Like somehow, poor mental health is thought to be an indicator of 'good performance, and we are taught to ignore the signs and not to wallow and remain silent on indicators of depression, and anxiety. Here the author using a feminist perspective corrals her experiences as a woman struggling with mental health, torn between her responsibilities at home and soon to be academic, with authenticity and vulnerability not often expressed in more conventional research methods.

\subsubsection{Becoming the first female Ph.D. in my family and losing my father}

Through the last 21 months of my Ph.D. journey, I was sucked up in my dissertation. I was toiling in my write-up, working on interviews, going to the field, transcribing interviews, making notes, coding, working on the thematic analysis. Each conscious moment was consumed by furthering my studies-conversations around the dinner table and between meals revolved around my work. I was a zombie - manifestation of my Ph.D. and lost my sense of self. I had feigned a new identity: one that circum-

3 "Ph.D. Students Face Significant Mental Health Challenges", Science | AAAS, Last modified 2021, https://www.sciencemag.org/careers/2017/04/phd-students-face-significant-mental-health-challenges. 
ambulated my degree program.

I graduated in December of 2018. After the successful defense, I could not internalize that I had finally made it. The beginning of 2019, however, was a very tough time for us as a family, as in the following month, I lost my beloved father after a prolonged illness. My father had represented masculinity for me throughout my upbringing in ways that the world needed to apprehend and follow through his actions -supporting my mother with chores and showing emotions, even weeping. My parents' equal partnership developed my understanding of feminism, the way my father treated me mounted upon it. Nevermore was I refused anything because of my gender. My gender was never regarded as a likely constituent in the decisions my parents, especially my father, took. We were taught to speak our minds, chase our dreams, be confident, and be our individual selves unapologetically. My father was the sole reason I ended up on this path; we used to have long discussions on philosophy, ethics, politics, and how to make the next career move. His demise was so hard to fathom, I did not know what I was doing and for whom? Is my life even worth it anymore? The whole notion that 'Hey, I'm a doctor now' did not sit well with me. It was such an anticlimax to the whole "Ph.D. journey."

\section{Final Thoughts}

This study was an attempt to add to the body of literature and offers a profoundly esoteric account. I tried to reflect on my experience as a Ph.D. scholar, the ebbs, and the flows of my doctoral journey. The use of autoethnography as a methodological approach is still relatively unexplored in this region's academic circles. It has provided me an approach to converge on my doctoral research experiences to be the "unit of analysis." Though a tad bit enthusiastic on my part, I intended to introduce a type widely missing from the academic scholarship that is to have stories of Ph.D. scholars' research encounters and experiences, similar to adventure anecdotes rather than dummies-101. Similar to adventure stories, the before-mentioned narratives would lend a lens into the junctions of various personalities and "the" exclusive Ph.D. experience.

\section{References}

Anderson, L. (2006). Analytic Autoethnography. Journal of Contemporary Ethnography, 35(4), 373-395. https://doi.org/10.1177/0891241605280449

Ban, R., \& Scott, V. (2021). I have your words in my head!: A collaborative autoethnography depicting the story of a PhD student's journey. NSUWorks. Retrieved 21 April 2021, from https://nsuworks.nova.edu/ tqre/ninth/day3/14/.

Barnes, B. J., \& Randall, J. (2012). Doctoral student satisfaction: An examination of disciplinary, 
enrollment, and institutional differences. Research in Higher Education, 53(1), 47-75. https://doi. org/10.1007/s11162-011-9225-4

Berry, K. (2006). Implicated audience member seeks understanding: Reexamining the "gift" of autoethnography. International Journal of Qualitative Methods, 5(3), 94-108

Bochner, A. P. (2000). Criteria against ourselves. Qualitative Inquiry, 6(2), 266-272.

Boylorn, R. M. (2006). E pluribus unum (out of many, one). Qualitative Inquiry, 12(4), 651-680.

Brydon, K., \& Fleming, J. (2011). The journey around my PhD: Pitfalls, insights and diamonds. Social Work Education, 30(8), 995-1011. https://doi.org/10.1080/02615479.2010.527936

Burnier, D. (2006). Encounters with the self in social science research: A political scientist looks at autoethnography. Journal of Contemporary Ethnography, 35(4), 410-418.

Butz, D., \& Besio, K. (2009). Autoethnography. Geography Compass, 3(5), 1660-1674.

Chang, H. (2008). Autoethnography as method. Walnut Creek, CA: Left Coast Press.

Creswell, J. (2007). Qualitative inquiry $\mathcal{E}$ research design: Choosing among the five approaches. Thousand Oaks, CA: Sage.

Duncan, M. (2004). Autoethnography: Critical appreciation of an emerging art. International journal of qualitative methods, 3(4), 28-39.

Durell, S. (2016). "Welcome to the real world" inclusive research with people with learning disabilities: A doc- toral journey. The Qualitative Report, 21(12), 2308-2330.

Ellis, C., 2004. The Ethnographic I: A Methodological Novel About Autoethnography. Walnut Creek, CA: AltaMira Press.

Ellis, C. (2007). Telling secrets, revealing lives: Relational ethics in research with intimate others. Qualitative Inquiry, 13(1), 3-29.

Ellis, Carolyn \& Bochner, Arthur. (2000). Autoethnography, Personal Narrative, Reflexivity: Researcher as Subject, in N. K. Denzin \& Y. S. Lincoln (Eds.), Handbook of Qualitative Research (2 ${ }^{\text {nd }}$ Ed.), Sage Publications, p. 733-768.

Ellis, C., \& Bochner, A. (2006). Analyzing Analytic Autoethnography: An Autopsy. Journal Of Contemporary Ethnography, 35(4), 429-449. doi: 10.1177/0891241606286979

Ellis, C., Adams, T.E., \& Bochner, A. (2010). Autoethnography: An Overview. Historical Social Research, 12(1), 273-290.

Ettorre, E. (2005, November). Gender, older female bodies and autoethnography: Finding my feminist voice by telling my illness story. In Women's Studies International Forum (Vol. 28, No. 6, pp. 535 546). Pergamon. 
Golafshani, N. (2003). Understanding Reliability and Validity in Qualitative Research. The Qualitative Report, 8(4), 597-606

Grant, A. (2010). Writing the reflexive self: An autoethnography of alcoholism and the impact of psychotherapy culture. Journal of Psychiatric and Mental Health Nursing, 17(7), 577-582

Greenhalgh, S. (2001), Under the medical gaze: facts and fictions of chronic pain, Berkeley: University of California Press.

Hayano, D. M. (1979). Auto-ethnography: Paradigms, problems, and prospects. Human organization, 38(1), 99-104.

Heywood, R. (2020). Autoethnography for Extraterrestrials. Journal Of Autoethnography, 1(2), 175-185. doi: $10.1525 /$ joae.2020.1.2.175

Holt, N. (2001). Beyond technical reflection: Demonstrating the modification of teaching behaviors using three levels of reflection. AVANTE-ONTARIO-, 7(2), 66-76.

Hooks. (2000) Feminist theory: from margin to centre. Cambridge, MA: South End Press.

Hope, K., \& Waterman, H. A. (2003). Praiseworthy pragmatism? Validity and action research. Journal of Advanced Nursing, 44(2), 120-127.

Hyun, J. K., Quinn, B. C., Madon, T., \& Lustig, S. (2006). Graduate student mental health: Needs assessment and utilization of counseling services. Journal of College Student Development, 47(3), 247-266.

Introduction to Feminist Research. (n.d). www2.unb.ca. Retrieved 7 May 2021, from http://www2.unb. $\mathrm{ca} /$ parl/research.htm

Johnson, B., Batia, A. S., \& Haun, J. (2008). Perceived stress among graduate students: Roles, responsibilities, \& social support. VAHPERD Journal, 29(3), 31-36.

Jones, S. H. (2005). Autoethnography: making the personal political. In N. K. Denzin, \& Y. S. Lincoln (Eds.), The Sage Handbook of Qualitative Research (3 ed., pp. 763-792). Thousand Oaks, CA: Sage Publications.

Koch, T., \& Harrington, A. (1998). Reconceptualizing rigour: The case for reflexivity. Journal of Advanced Nursing, 28(4), 882-890.

Krizek, R. L. (2003). Ethnography as excavation of personal narrative. In R. P. Clair (Ed.), Expressions of ethnography: novel approaches to qualitative methods (pp. 141-151).

Lincoln, Y. S., \& Guba, E. G. (1985). Naturalistic inquiry. Beverly Hills, CA: Sage.

Lorde, A. (1997). The cancer journals: Special edition. San Francisco, CA: Aunt Lute

Mackie, S. A., \& Bates, G. W. (2019). Contribution of the doctoral education environment to PhD candidates' mental health problems: A scoping review. Higher Education Research $\mathcal{E}$ Development, 38(3), 565-578. https://doi.org/10.1080/07294360.2018.1556620 
Mantai, L., \& Dowling, R. (2015). Supporting the PhD journey: Insights from acknowledgements. International Journal for Researcher Development, 6(2), 106-121. https://doi.org/10.1108/IJRD-03-2015-0007

Mason, A., \& Hickman, J. (2019). Students supporting students on the PhD journey: An evaluation of a mentoring scheme for international doctoral students. Innovations in Education and Teaching International, 56(1), 88-98.

Mayan, M. J. (2001). An introduction to qualitative methods: A training module for students and professionals. Edmonton, Alberta, Canada.

McMillan, C., \& Ramirez, H. (2016). Autoethnography as Therapy for Trauma. Women $\mathcal{E}$ Therapy, 39(34), 432-458. doi: 10.1080/02703149.2016.1117278

McPhail-Bell, K., \& Redman-MacLaren, M. L. (2019). A Co/Autoethnography of Peer Support and PhDs: Being, Doing, and Sharing in Academia. The Qualitative Report, 24(5), 1087-1105. Retrieved from https://nsuworks.nova.edu/tqr/vol24/iss5/12

Mcllveen, P. (2008). Autoethnography as a method for reflexive research and practice in vocational psychology. Australian Journal of Career Development, 17(2), 13-20.

Méndez, M. (2013). Autoethnography as a research method: Advantages, limitations and criticisms. Colombian Applied Linguistics Journal, 15(2), 279-287.

Morse, J. M., Barrett, M., Mayan, M., Olsen, K., \&. Spiers, J. (2002). Verification strategies for establishing reliability and validity in qualitative research. International Journal for Qualitative Methods, 1(2), 13-22.

Morse, J. M., \& Richards, L. (2002). Readme first for a user's guide to qualitative methods. Los Angeles: Publications, Inc.

Muncey, T. (2005). Doing autoethnography. International journal of qualitative methods, 4(1), 69-86.

Neuman, W. L. (1994). Social research methods: Qualitative and quantitative approaches. Needham Heights, MA: Allyn and Bacon.

Ngunjiri, F. W., Hernandez, K. A. C., \& Chang, H. (2010). Living autoethnography: Connecting life and research. Journal of research practice, 6(1), 1-17.

O'Byrne, P. (2007). The advantages and disadvantages of mixing methods: An analysis of combining traditional and autoethnographic approaches. Qualitative Health Research, 17(10), 1381-1391.

Oswalt, S. B., \& Riddock, C. C. (2007). What to do about being overwhelmed: Graduate students, stress and university services. College Student Affairs Journal, 27(1), 24-44.

Ottenberg, Simon (1990) 'Thirty Years of Fieldnotes: Changing Relationships to the Text', in R. Sanjek (ed.) Fieldnotes: The Makings of Anthropology, pp. 139-60. Ithaca, NY: Cornell University Press.

Pace, S. (2012). Writing the self into research: Using grounded theory analytic strategies in autoethnography. TEXT Special Issue: Creativity: Cognitive, Social and Cultural Perspectives, 1-22. 
Pretorius, L., Macaulay, L., \& Cahusac de Caux, B. (2019). Wellbeing in doctoral education. Singapore: Springer.

Poulos, C. N. (2006). The ties that bind us, the shadows that separate us: Life and death, shadow and (dream) story. Qualitative Inquiry, 12(1), 96-117.

Ramanayake, U. (2020). My Doctoral Journey: An Autoethnography of Doing Sensitive Research in a Different Cultural Context. International Journal of Doctoral Studies, 15, 559-573.

Reed-Danahay, D. E. (1997). Auto/ethnography: Rewriting the self and the social. Oxford, UK: Berg.

Richardson, L. (1994). Writing: a method of inquiry. In N. K. Denzin \& Y. S. Lincoln (Eds.), Handbook of qualitative research (pp. 516-529). Thousand Oaks, CA: Sage.

Riessman, C. (2008). Narrative methods for the human sciences (1st ed.). Los Angeles: CA: Sage Publications, Inc.

Robbins, W. (1996). Dollars and Sense, or, Reflections and Projections of a Feminist Researcher, in Memories and Visions: Celebrating 20 Years of Feminist Research with CRIAW/ICREF, 1976-1996. Ed. Linda Clippingdale. Ottawa: CRIAW/ICREF, 1.170-77

Rolfe, G. (2006). Validity, trustworthiness and rigour: quality and the idea of qualitative research. Journal of advanced nursing, 53(3), 304-310.

Sandelowski, M. (1986). The problem of rigor in qualitative research. Advances in Nursing Science, 8(3), $27-37$.

Schmidt, M., \& Hansson, E. (2018). Doctoral students' well-being: a literature review. International journal of qualitative studies on health and well-being, 13(1) 1508171. https://doi.org/10.1080/17482 631.2018 .1508171

Schwandt, T. A. (1996). Farewell to criteriology. Qualitative Inquiry, 2(1), 58-72.

Smith, D. E. (1987). The everyday world as problematic: A feminist sociology. Toronto: University of Toronto Press.

Smith, R. L., Maroney, K., Nelson, K. W., Lable, A., \& Abel, H. S. (2006). Doctoral programs: Changing high rates of attrition. Journal of Humanistic Counseling, Education and Development, 45(1), $17-31$.

Sparkes, A. C. (1996). The fatal flaw: A narrative of the fragile body-self. Qualitative inquiry, 2(4), 463-494.

Sparkes, A. C. (2007). Embodiment, academics, and the audit culture: A story seeking consideration. Qual itative research, 7(4), 521-550.

Stern, D. M. (2014). “He Won't Hurt Us Anymore”: A Feminist Performance of Healing for Children Who Witness Domestic Violence. Women's Studies in Communication, 37(3), 360-378.

Stratton, J. S., Miekle, A., Kirshenbaum, S., Goodrich, A., \& McRae, C. (2006). Finding a balanced 
life: Factors that contribute to life satisfaction in graduate students. Journal of College and Character, $7(8), 1-10$.

Stubb, J., Pyhältö, K., \& Lonka, K. (2011). Balancing between inspiration and exhaustion: PhD students' expe- rienced socio-psychological well-being. Studies in Continuing Education, 33(1), 33-50.

Toews, J., Lockyer, J., Dobson, D., Simpson, E., Brownell, A., Brenneis, F., MacPherson KM, \& Cohen GS. (1997). Analysis of stress levels among medical students, residents, and graduate students at four Canadian schools of medicine. Academic Medicine, 72(11), 997-1002.

Tracy, S. J. (2010). Qualitative quality: Eight big-tent criteria for excellent qualitative research. Qualitative Inquiry, 16(10), 837-851.

Tsalach, C. (2013). Between silence and speech: Autoethnography as an otherness-resisting practice. Qualitative Inquiry, 19(2), 71-80.

Wall, S. (2008). An Autoethnography on Learning About Autoethnography. International Journal Of Qualitative Methods, 5(2), 146-160.

Wyatt, J. (2006). Psychic distance, consent, and other ethical issues: Reflections on the writing of "A Gentle Going?". Qualitative inquiry, 12(4), 813-818.

Wang, T., \& Li, L. Y. (2011). 'Tell me what to do' vs. 'guide me through it': Feedback experiences of international doctoral students. Active Learning in Higher Education, 12(2), 101-112.

Winter, G. (2000). A comparative discussion of the notion of validity in qualitative and quantitative research. The qualitative report, 4(3), 1-14.

Yonelinas, A. P., Aly, M., Wang, W. C., \& Koen, J. D. (2010). Recollection and familiarity: Examining controversial assumptions and new directions. Hippocampus, 20(11), 1178-1194. 